\title{
Short-term oral administration of risperidone induces pancreatic damage and hyperamylasemia in Sprague-dawley rats
}

\author{
Rehmat Shah ${ }^{1,2, *}$, Fazal Subhan', Syed Muhammad Sultan³, Gowhar Ali ${ }^{1}$
}

\begin{abstract}
${ }^{1}$ Pharmacology Research Laboratory, Department of Pharmacy, University of Peshawar, Khyber Pakhtunkhwa, Pakistan, ${ }^{2}$ Government Moulvi Ameer Shah Memorial Hospital, Peshawar, Khyber Pakhtunkhwa, Pakistan, ${ }^{3}$ Department of Psychiatry, Khyber Medical College, Peshawar/Khyber Teaching Hospital, Peshawar, Khyber Pakhtunkhwa, Pakistan
\end{abstract}

\begin{abstract}
Risperidone is an atypical antipsychotic acting mainly as a dopamine $\mathrm{D}_{2}$ and serotonin $5-\mathrm{HT}_{2}$ receptors antagonist prescribed in the treatment of schizophrenia and various affective disorders. Risperidone has been reported to be associated with weight gain, panreatitis and type 2 diabetes mellitus. Various mechanisms of risperidone-induced toxicities have been reported but the histology of tissues especially pancreas has never been studied. Therefore, the current study was designed to elucidate the toxic effects of chronic administration of risperidone on pancreas, liver and kidneys. Animals (rats) of either gender were divided into two groups, the risperidone and control groups. Risperidone was administered in a dose of $2.5 \mathrm{mg} / \mathrm{kg} / \mathrm{d}$ for three weeks. The controls received acidified saline only. Both the groups received restricted diet $(20 \mathrm{~g} / 12 \mathrm{~h})$. The body weight and level of random blood sugar (RBS) were measured on a weekly basis. The levels of lipase and amylase were determined at the conclusion of the experiment. At the end of the experiment, the tissues were dissected out for histopathological evaluation. Risperidone showed no weight gain, hyperglycemia or rise in the level of lipase $(\mathrm{P}>0.05)$; however, the level of amylase was raised $(* * * \mathrm{P}<0.05)$. Histological examination under light microscope showed no hepatotoxicity, nephrotoxicity but did show damage to the pancreas. The findings of this study indicated that the incidence of adverse effects associated with risperidone could be prevented/alleviated/delayed by allowing restricted diet.
\end{abstract}

Keywords: Risperidone/antipsychotics/oral administration/effects. Histopathology. $\mathrm{D}_{2}$ antagonist. Pancreas.

\section{INTRODUCTION}

Risperidone is an atypical antipsychotic which is used in the treatment of schizophrenia and other psychiatric problems. It has got $\mathrm{D}_{2}$ and $5 \mathrm{HT}_{2}$ antagonistic properties which, on one hand, render it an effective antipsychotic drug but, on the other hand, result in unwanted effects including hyperphagia, weight gain, hyperglycemia and pancreatitis (Koller et al., 2003a; Pouzet et al., 2003; Wirshing et al., 1998). Weight gain is believed to be due to hyperphagia which, in turn, due to its anti-dopaminergic, anti-serotonergic properties and $\mathrm{H}_{1}$ blocking activities. Several researchers have

\footnotetext{
*Correspondence: R. Shah. Department of Pharmacy, University of Peshawar, Peshawar, Pakistan and Pharmacist, Government Moulvi Ameer Shah Memorial (MASM) Hospital, Peshawar, Pakistan. Tel: +92 091 9216750; Cell: +92 3459824130 / Fax: +92-91921813. E-mail: rehmatshah@uop.edu.pk
}

postulated dietary interventions and control on calories to prevent weight gain and subsequent untoward effects like dyslipidemia, hyperglycemia and pancreatitis (Fountaine et al., 2010; Gohlke et al., 2012). Food and Drug Administration's MedWatch Surveillance System as well as published reports have indicated one hundred ninety-two patients with pancreatitis receiving one or the other antipsychotic, with $16 \%$ due to risperidone only (Koller et al., 2003a; Koller et al., 2003b).

Halici and his colleagues have reported that $\mathrm{i} / \mathrm{p}$ administration of risperidone $(0.5$ and $1 \mathrm{mg} / \mathrm{kg})$ for 6 weeks did not affect the architecture of liver of rats (Halici et al., 2008). They while using both light and electron microscope, report no significant changes in total liver cells count and numerical density of liver of risperidone treated rats and placebo. Stereological results were confirmed from structural and ultrastructural examination of liver and concluded that neither low nor higher doses 
of risperidone proved hepatotoxic (Halici et al., 2008). Nephrotoxicity with chronic administration (6 weeks) of risperidone $(0.5$ and $1 \mathrm{mg} / \mathrm{kg} / \mathrm{d})$ has been reported with postulation that it was due to oxidative stress (Mustafa et al., 2012). It has been reported that risperidone causes elevation of amylase and lipase (Koller et al., 2003a), but there are rare reports giving a clear idea about its toxic effects on the architecture of pancreas. Dietary and pharmacological interventions have been recommended to lessen the APDs-associated alarming events (Gohlke et al., 2012), but have never been reported.

We are aimed, in this study, to assess the effects of risperidone $(2.5 \mathrm{mg} / \mathrm{kg} / \mathrm{d})$ after 21 days oral administration, on selected tissues, including pancreas, liver and kidneys, and on blood glucose, body weight, amylase and lipase, while allowing restricted quantity of food $(20 \mathrm{~g} / 12 \mathrm{~h})$, with free access to water.

It is relevant to mention that risperidone is available as tablets and syrups in conventional formulations in the market while its sustained release and injectable formulations are under investigations (Badshah et al., 2011; Fleischhacker et al., 2003; Siafaka et al., 2015).

\section{MATERIAL AND METHODS}

\section{Animals}

Sprague-dawley rats were bred in the animal house, Department of Pharmacy, University of Peshawar. Total 14 animals of either sex, weighing 160 to $300 \mathrm{~g}$, were housed in plastic cages at a control climate (19 to $23{ }^{\circ} \mathrm{C}$ ). The rats were maintained on $12 \mathrm{~h}$ reversed light-dark cycle (light on between 21:00 and 9:00 h), started 2 weeks before the commencement of dosing. The animals were then equally stratified into 2 groups, each comprising of 7 animals, one for each drug and the control. All animals were having free access to water and restricted quantity of food $(20 \mathrm{~g} / 12 \mathrm{~h} /$ animal) (Pouzet et $a l ., 2003)$. All the procedures were approved from the ethical committee (approval number, 02/EC-14/Pharm), Department of Pharmacy, University of Peshawar and were in strict accordance with Animals Scientific Procedures Act, 1986, UK.

\section{Procedures}

\section{Drugs treatment}

The animals were kept fasted for 24 hours before the first dose was administered. Risperidone was generously gifted by Global Pharmaceutical Company Private Islamabad, Pakistan. It was used orally in a dose of $2.5 \mathrm{mg} / \mathrm{kg} / \mathrm{d}$ based on the previous data available (Terry Jr et al., 2003). Risperidone was formulated by dissolving in small quantity of $0.1 \mathrm{~N}$ acetic acid followed by volume make-up with normal saline in a ratio of 1 to 100 . Controls were administered normal saline in a volume based on body weight (not greater than $5 \mathrm{~mL} / \mathrm{kg} / \mathrm{d}$ ). Both of the solutions were administered orally by oral gavage method. Fresh solutions were prepared each day (Terry et al., 2003).

\section{Body weight measurement}

The animals were weighed before the administration of the first dose as well as weekly before the administration of next newly calculated dose.

\section{Random Blood Sugar (RBS)}

Randome Blood Glucose (RBS) was measured weekly, using Abbot Glucometer.

\section{Amylase and lipase levels}

Both amylase and lipase were determined at the end of the experiment. Animals were euthanized using ketamine, (Ali et al., 2013; Shah et al., 2015), in order to minimize stress and pain to the animals during blood collection. The blood was collected by cardiac puncture, centrifuged, and the serum collected was stored at 4-8 ${ }^{0} \mathrm{C}$ till analyzed. The serum collected was analyzed for levels of amylase and lipase using single beam spectrophotometer (Unico 1100RS). The amylase and lipase kits (Cat. No. LI 188, 20 x $2.5 \mathrm{ml}$ ), were purchased from Randox Laboratories Limited, UK.

\section{Hematoxylin and Eosin $(H \& E)$ Staining}

The animals were euthanized, selected tissues including pancreas, liver and kidneys were isolated, washed with Phosphate Buffered Saline (PBS), sliced into small pieces and fixed for not less than 6 hours. The fixed samples of tissues were further sliced into small pieces of 3-5 $\mathrm{mm}$ and embedded separately in paraffin blocks. These blocks were sectioned using microtome (SLEE MAINZ, CUT 5062). Sections of different sizes ( $3 \mu, 5 \mu$ and $10 \mu$ ) were taken and stained using $\mathrm{H} \& \mathrm{E}$ staining technique. The stains such obtained were analyzed under light microscope (LABOMED LX400) equipped with camera (iVu 3100). The images obtained were labeled, saved and interpreted for any drug induced changes (Ali et al., 2013; Shah et al., 2015).

\section{STATISTICAL ANALYSIS}

All statistical analysis was carried out using graph 
pad prism version 5 (Graph Pad Software Inc. San Diego CA, USA) applying 1-way ANOVA (Bonferroni's Multiple Comparison Test) or unpaired t-test where applicable. Data were expressed as mean \pm standard error of the mean (SEM). $\mathrm{P}<0.05$ was considered as statistically significant.

\section{RESULTS}

\section{Percent weight gain}

Risperidone showed no significant change in body weight (not significant), as compared to normal saline, as depicted in Figure 1.

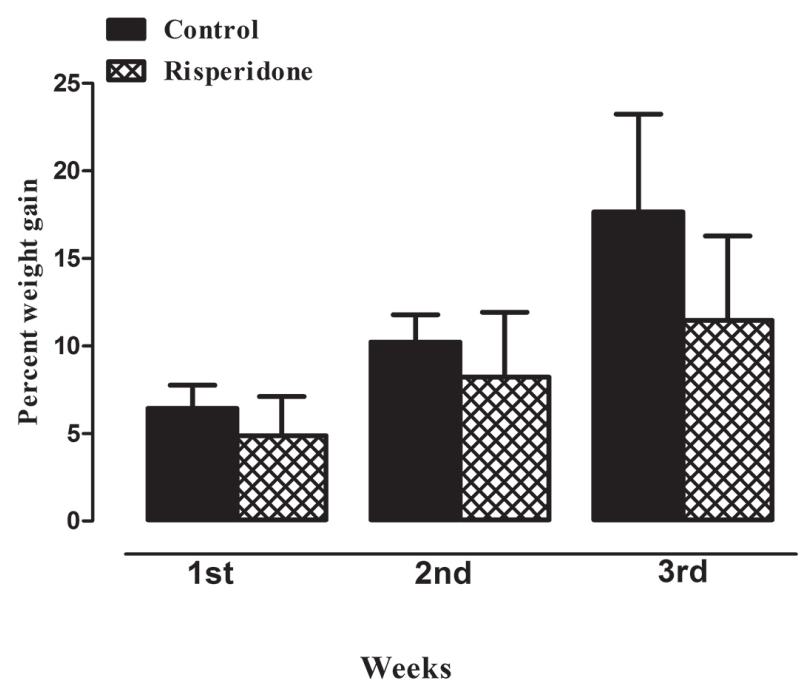

FIGURE 1 - Effect of risperidone on percent weight gain: Three weeks treatment of rats treated with risperidone $(2.5 \mathrm{mg} / \mathrm{kg} / \mathrm{d})$ orally showing no significant rise in percent weight (ANOVA followed by Bonferroni's Multiple Comparison Test, not significant).

\section{Random Blood Sugar (RBS)}

Random Blood Sugar(RBS) was determined weekly using Abbott Glucometer. Risperidone did not show significant rise in blood sugar (not significant). The results are shown in Figure 2.

\section{Pancreatic Functions Tests (PFTs)}

Risperidone was tested for its effects on amylase and lipase applying unpaired t-test. Risperidone showed significant rise in the level of amylase $(* * * \mathrm{P}<0.001)$ but lipase remained unaffected. The results are shown in Figures 3 and 4.

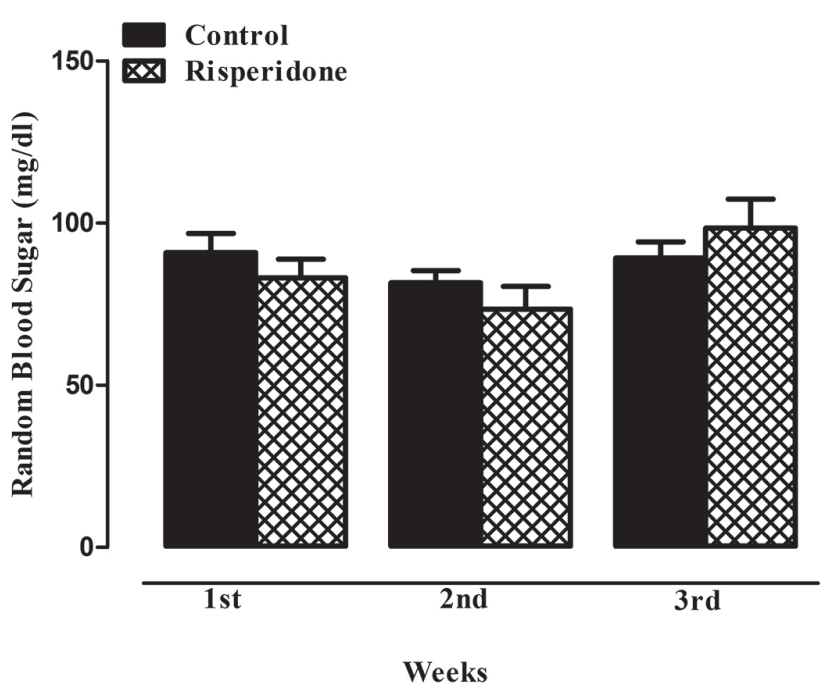

FIGURE 2 - Effect of risperidone on RBS: Three weeks treatment of rats treated with risperidone $(2.5 \mathrm{mg} / \mathrm{kg} / \mathrm{d})$ orally showing no significant rise in random blood sugar (RBS) (mg/dL) (ANOVA followed by Bonferroni's Multiple Comparison Test, not significant).

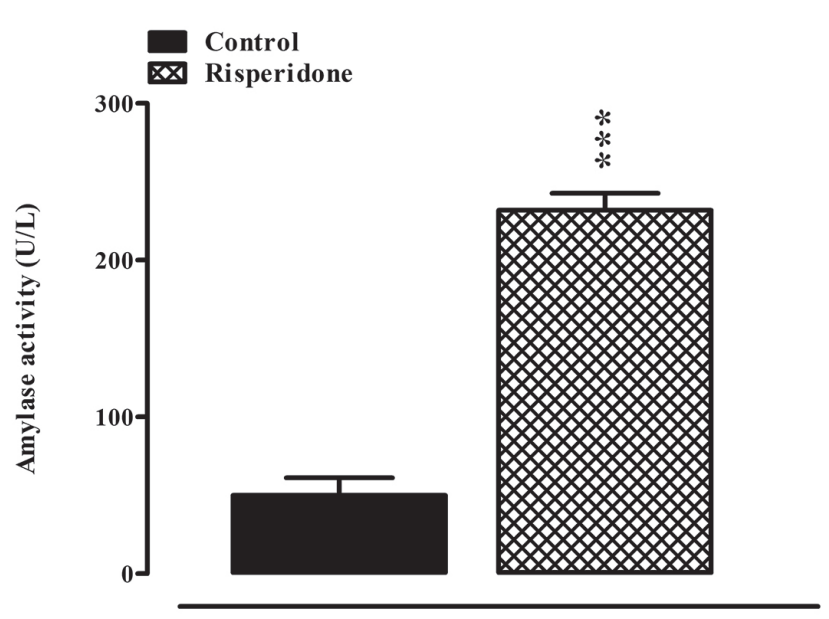

Treated Groups

FIGURE 3 - Effect of Risperidone $(2.5 \mathrm{mg} / \mathrm{kg} / \mathrm{d})$ on amylase: Three weeks oral treatment of rats exhibited significant increase in amylase level $(\mathrm{U} / \mathrm{L})$ in risperidone treated group as compared to control $(* * * \mathrm{P}<0.001)$ (unpaired t-test).

\section{HISTOLOGICAL STUDY}

\section{Effect on pancreas}

The islets of Langerhans were shown clearly packed and compacted in the controls whereas the islets of Langerhans in the pancreas of risperidone treated rats seemed scattered showing derangement of pancreatic islets of Langerhans, as shown in Figures 5 and 6. 


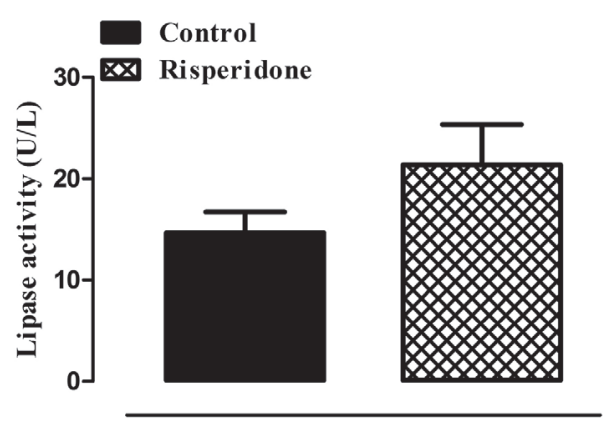

Treated Groups

FIGURE 4 - Effect of Risperidone $(2.5 \mathrm{mg} / \mathrm{kg} / \mathrm{d})$ on lipase: Three weeks oral treatment of rats exhibited no significant increase in lipase level (U/L) in risperidone treated group as compared to control (not significant) (unpaired t-test).

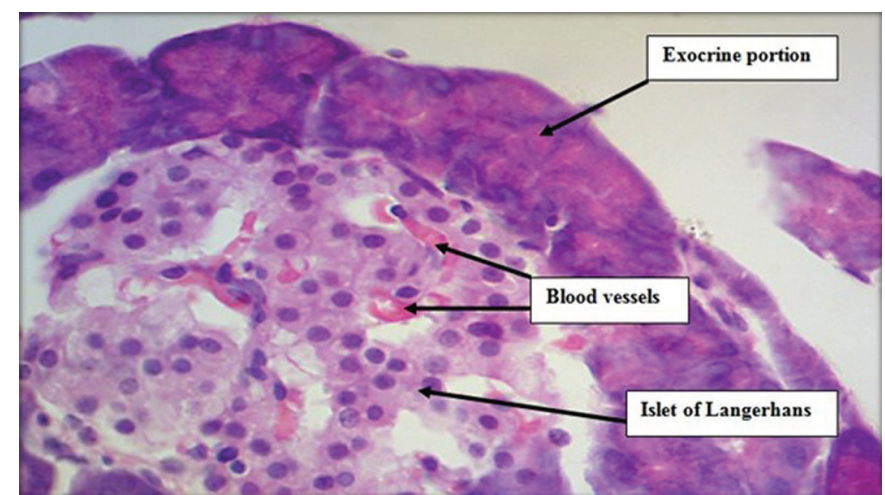

FIGURE 5 - Effect of normal saline on the pancreas of rats $(\mathrm{H} \& \mathrm{E}, 400 \mathrm{x}, 5 \mu$ ): Representative image of pancreas of rats treated with normal saline orally for three weeks showing islets of Langerhans, packed as compact and intact glandular mass.

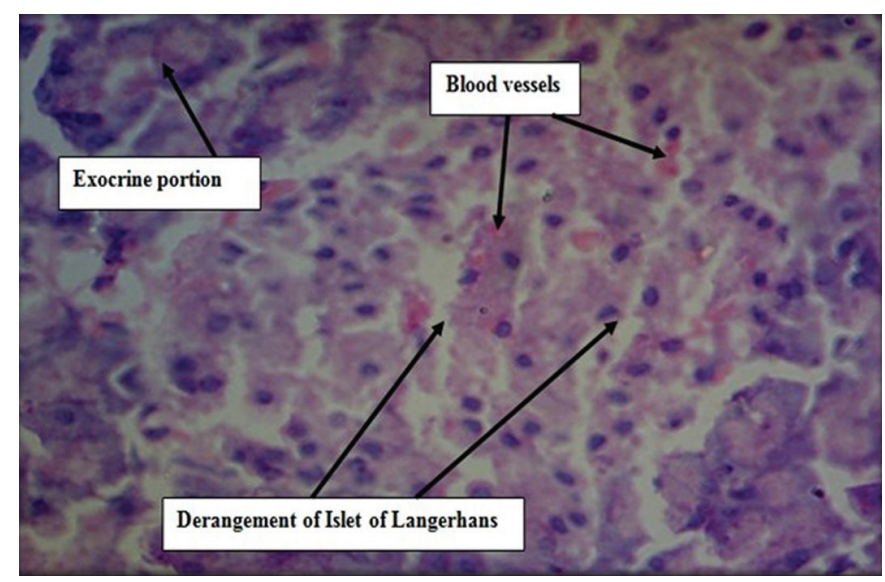

FIGURE 6 - Risperidone-induced histopathological changes in pancreas (H \& E, 400x, $5 \mu$ ): Representative image of pancreas of rats treated with risperidone $(2.5 \mathrm{mg} / \mathrm{kg} / \mathrm{d})$ orally for three weeks showing derangement of islets of Langerhans, lacking compaction of glandular cells as compared to rats treated with normal saline.

\section{Effect on kidneys}

As shown in Figures 7 to 11, the glomeruli with intact structure and blood perfusion were identified in the kidneys of rats. Bowman's capsules with intact endothelium were observed both in controls and risperidone treated rats. No prominent architectural damage could be seen.

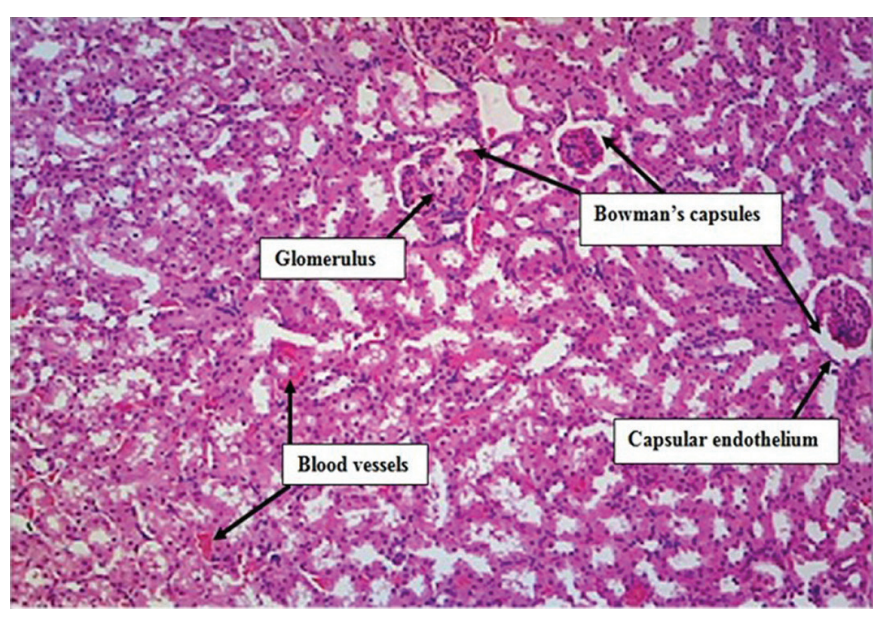

FIGURE 7 - Effect of normal saline on the kidneys of rats $(\mathrm{H} \& \mathrm{E}, 100 \mathrm{x}, 5 \mu$ ): Representative image of kidney of rats treated with normal saline orally for three weeks showing thin walled endothelium of Bowman's capsule, glomeruli with intact cellular borders, blood perfusion and convoluted tubules.

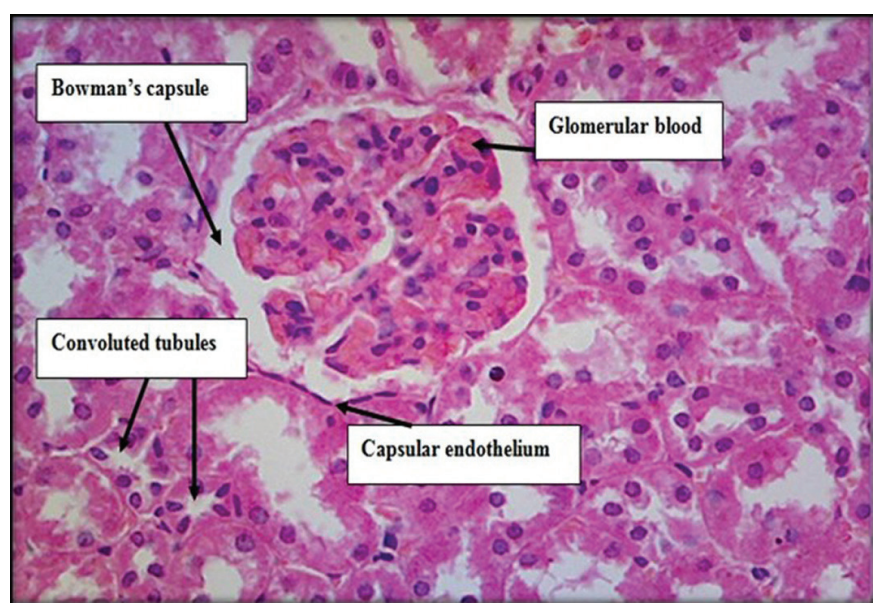

FIGURE 8 - Effect of normal saline on the kidneys of rats $(\mathrm{H} \& \mathrm{E}, 400 \mathrm{x}, 5 \mu)$ : Representative image of kidney of rats treated with normal saline orally for three weeks showing thin walled endothelium of Bowman's capsule, glomerulus with intact cellular borders, blood perfusion and convoluted tubules.

\section{Effect on liver}

The liver of rats of both groups seemed unaffected. Central vein and hepatic plates radiating outwards were seen normal in controls and risperidone treated rats. Risperidone 


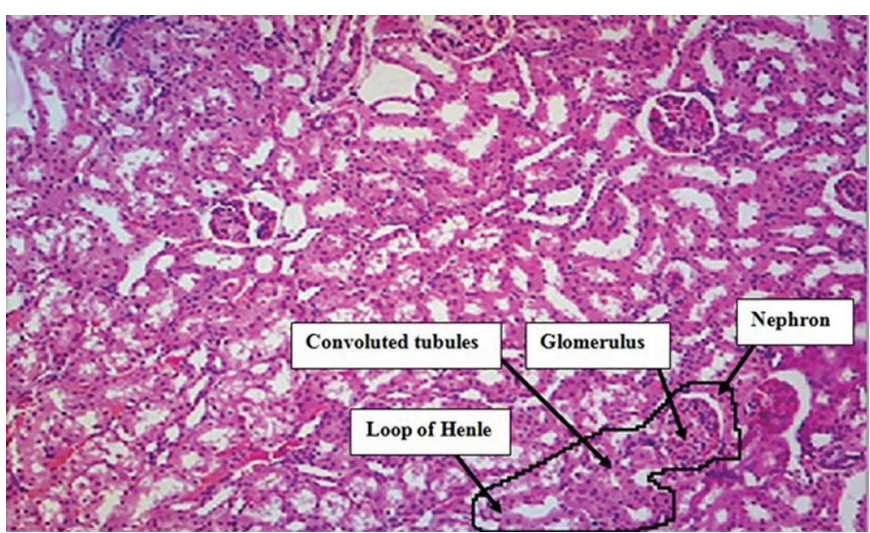

FIGURE 9 - Effect of risperidone on the kidneys of rats $(2.5 \mathrm{mg} / \mathrm{kg} / \mathrm{d})(\mathrm{H} \& \mathrm{E}, 100 \mathrm{x}, 5 \mu)$ : Representative image of kidney of rats treated with risperidone $(2.5 \mathrm{mg} / \mathrm{kg} / \mathrm{d})$ orally for three weeks showing thin walled endothelium of Bowman's capsule, glomeruli with intact cellular borders, blood perfusion and convoluted tubules.

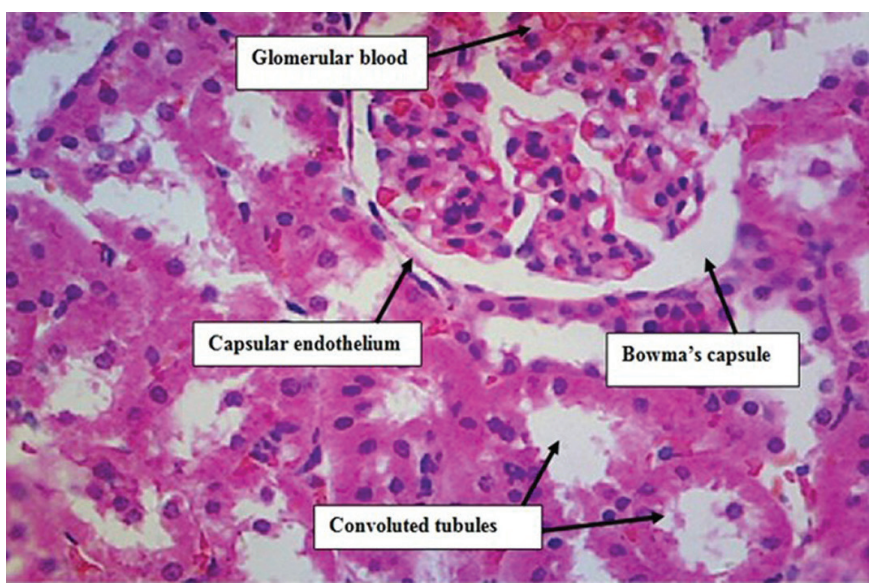

FIGURE 10 - Effect of risperidone on the kidneys of rats $(2.5 \mathrm{mg} / \mathrm{kg} / \mathrm{d})(\mathrm{H} \& \mathrm{E}, 400 \mathrm{x}, 5 \mu)$ : Representative image of kidney of rats treated with risperidone orally for three weeks showing thin walled endothelium of Bowman's capsule, glomeruli with intact cellular borders, blood perfusion and convoluted tubules.

treatment did not insult the parenchyma of liver showing normal architecture, as shown in Figures 12 and 13.

\section{DISCUSSION}

Risperidone has been classed among the most effective and fundamental tools in treating schizophrenia and other related disorders, but body weight gain (Baptista et al., 2004), hyperglycemia (Baptista et al., 2004), pancreatitis (Koller et al., 2003a) and nephrotoxicity (Mustafa et al., 2012) have been postulated among the major adverse drug reactions associated with risperidone. The mechanism of these adverse events has, however, still not been unveiled successfully. Excessive food

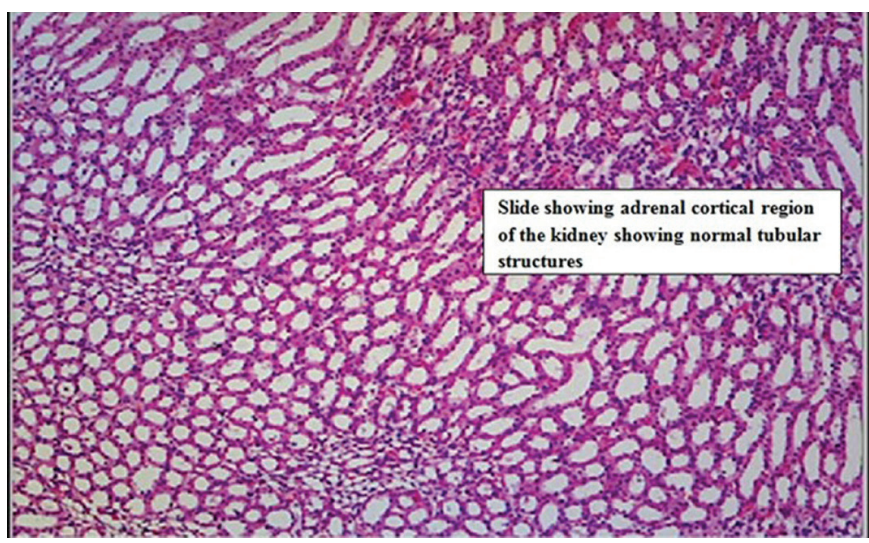

FIGURE 11 - Effect of risperidone on the kidneys of rats $(2.5 \mathrm{mg} / \mathrm{kg} / \mathrm{d})(\mathrm{H} \& \mathrm{E}, 100 \mathrm{x}, 5 \mu)$ : Representative image of kidney of rat treated with risperidone orally for three weeks showing intact cortical region of the kidney without any druginduced architectural insult.

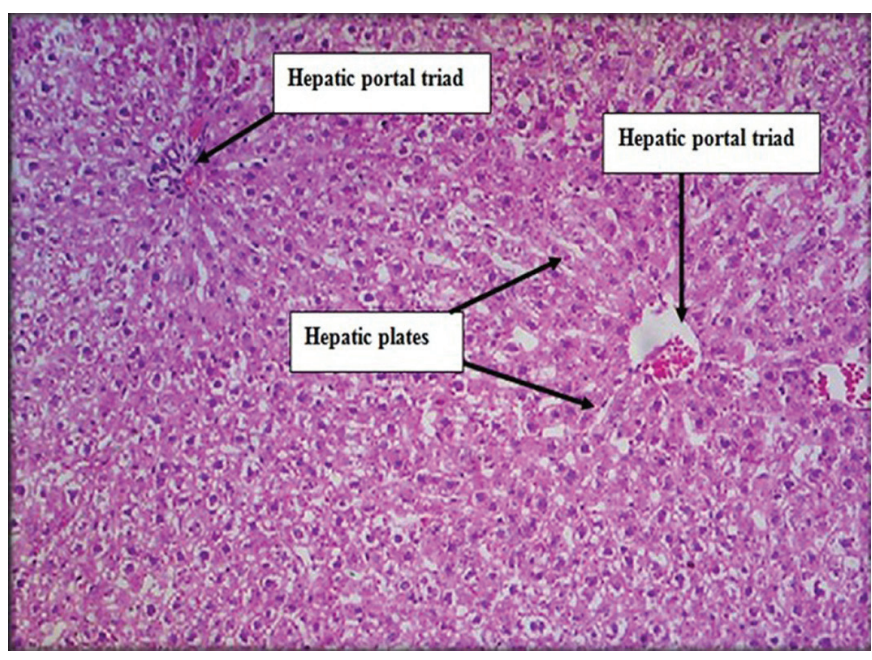

FIGURE 12 - Effect of risperidone on the liver of rats (H \& E, 100x, $3 \mu$ ): Representative images of liver of rats treated with normal saline orally for three weeks showing no hepatic architectural changes.

intake (Baptista et al., 2004), $\mathrm{H}_{1}$ antagonism (Baptista et al., 2004) and insulin resistance (Baptista et al., 2004) have been labeled as one of the causes of weight gain and hyperglycemia. We therefore modified the model and used diet restriction to exclude the involvement of excessive food intake in inducing these alarming events, and noticed no weight gain and hyperglycemia in the prescribed duration of treatment. In a placebo controlled, double blind crossover study, Fountain and his colleagues have reported weight gain in human healthy volunteers which was associated with excessive food intake and increased resting energy expenditure in antipsychotic treated rats as compared to placebo (Fountaine et al., 2010). In our study model, the least significant effect on 


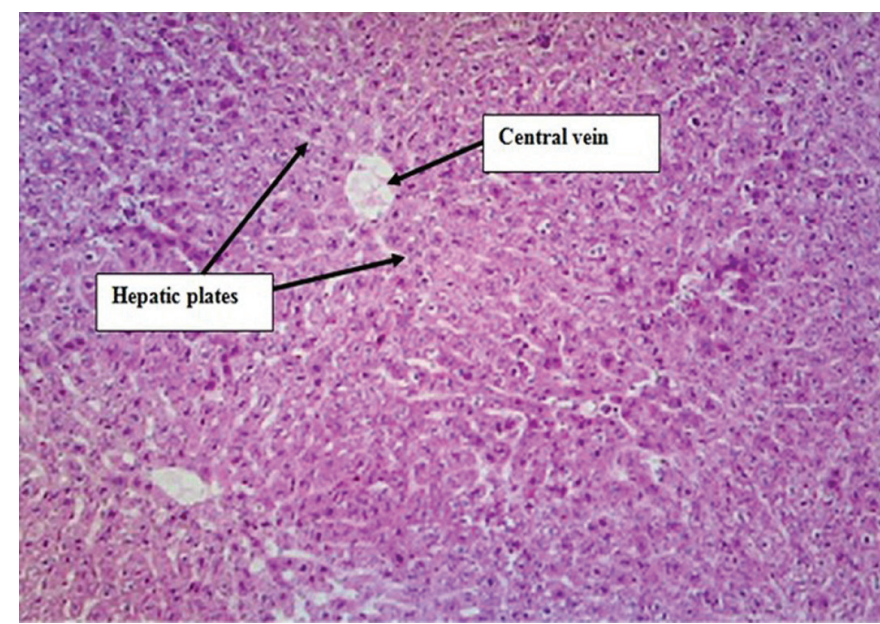

FIGURE 13 - Effect of risperidone on the liver of rats (H \& E, 100x, $3 \mu$ ): Representative images of liver of rats treated with risperidone $(2.5 \mathrm{mg} / \mathrm{kg} / \mathrm{d}$ orally for three weeks showing no hepatic architectural changes as compared to normal saline treated rats.

body weight and subsequent expected elevation in blood glucose is supposed to be due to access to restricted diet in risperidone treated rats.

The level of amylase was, however, elevated, while lipase remained unaffected, in our study. Contrary to this, Yamaguchi and his co-workers have reported ameliorative effect of risperidone on pancreatitis. They reported that risperidone significantly attenuated serum interleukin levels, amylase, lipase, platelets count, histological changes and mortality rate in choline-deficient, ethionine-supplimented diet-induced pancreatitis in mice (Yamaguchi et al., 2009). Random blood sugar can be easily tested by puncturing the tip of the tail which is not practicable for amylase and lipase for which minimum of $1 \mathrm{ml}$ blood is required each time and thus practically not possible in such small animals. This was the reason that both of the enzymes were tested at the conclusion of the experiment. The reason of these inconsistent findings could be; (1). Use of both genders though it is known that female rats are more sensitive than male (Baptista et al., 2004) (2). Use of restricted diet (20 $\mathrm{g} / 24 \mathrm{~h}$ ) (3). Single daily dosing is not sufficient to induce these pathologies (3). Risperidone might have lost/reduced its potency in solution form.

This is novelty of the study that the biochemistry of pancreas has been correlated with its histology. In most of the studies, either amylase or lipase has been studied but we have compared histopathology of pancreas with the enzymes released by it i.e. amylase and lipase. Derangement of islets of Langerhans lacking compaction of glandular cells was observed in risperidone treated rats which is supported by elevation in the level of amylase. Although hyperglycemia has not been observed, the histopathological changes in the architecture of pancreas and elevation of amylase warn about the induction of diabetes if the treatment is continued for a longer period of time. No studies have been found reporting the histopathological impact of risperidone on pancreas supported by biochemical assessment.

We did not notice any pathological changes in the architecture of kidneys and liver which is in line with previous studies (Halici et al., 2009; Mustafa et al., 2012). The liver of rats of both the groups seemed unaffected. Central vein and hepatic plates radiating outwards were seen normal in controls and risperidone treated rats. Risperidone treatment did not insult the parenchyma of liver showing normal architecture. Similarly, glomeruli with intact structure and blood perfusion were identified in the kidneys of rats. Bowman's capsule with intact endothelium was observed both in controls and risperidone treated rats. No prominent architectural damage could be observed.

The glucose-stimulated cholinergic pathway of insulin release is regulated by muscarinic $\mathrm{M}_{3}$ receptors which has been reported to be interfered by atypical antipsychotics including risperidone (Weston-Green, Huang, Deng, 2013). Our study supports this finding since risperidone and our previous findings about olanzapine showed that these drugs directly damage pancreatic islets (Shah et al., 2015). However, risperidone remains safe to both liver and kidneys.

\section{CONCLUSIONS}

Three weeks oral administration of risperidone $(2.5 \mathrm{mg} / \mathrm{d})$ in rats did not cause hyperglycemia, weight gain, architectural insult to kidneys and liver except derangement of beta cells of Langerhan in pancreas in our set model.

\section{LIMITATIONS}

The histopathology of kidney and liver was not correlated with renal and liver function tests respectively.

\section{ACKNOWLEDGMENTS}

We are thankful to Mr. Muhammad Salar, Assistant Professor, Department of Pharmacy, Abdul Wali Khan University, Mardan, Pakistan and Mr. Muhammad Shahid, Lecturer, Sarhad University of Science and Information Technology, Peshawar for their help and support in scientific interpretation of microscopic slides. We are also thankful to Global Pharmaceutical Company private, Islamabad, Pakistan, for the generous donation of risperidone. 


\section{REFERENCES}

Ali G, Subhan F, Islam NU, Ullah N, Shahid M, Ullah $\mathrm{S}$, et al. Comparative evaluation of gastroulcerogenic potential of nitrogen isoforms of salicyl alcohol and aspirin in rats: biochemical and histological study. Arch Pharm Res. 2013;37(7):916-926.

Badshah A, Subhan F, Rauf K, Bukhari NI, Shah K, Khan $\mathrm{S}$, et al. Development of controlled-release matrix tablet of risperidone: influence of methocel ${ }^{\circledR}$-and ethocel ${ }^{\circledR}$-based novel polymeric blend on in vitro drug release and bioavailability. AAPS PharmSciTech. 2011;12(2):525-533.

Baptista T, Zarate J, Joober R, Colasante C, Beaulieu S, Paez X, et al. Drug induced weight gain, an impediment to successful pharmacotherapy: focus on antipsychotics. Curr Drug Targets. 2004;5(3):279-299.

Fleischhacker WW, Eerdekens M, Karcher K, Remington G, Llorca PM, Chrzanowski W et al. Treatment of schizophrenia with long-acting injectable risperidone: a 12-month open-label trial of the first long-acting second-generation antipsychotic. J Clin Psychiatry. 2003;64 (10):1250-1257.

Fountaine RJ, Taylor AE, Mancuso JP, Greenway FL, Byerley LO, Smith SR, et al. Increased food intake and energy expenditure following administration of olanzapine to healthy men. Obesity (Silver Spring). 2010;18(8):1646-1651.

Gohlke JM, Dhurandhar EJ, Correll CU, Morrato EH, Newcomer $\mathrm{JW}$, Remington $\mathrm{G}$, et al. Recent advances in understanding and mitigating adipogenic and metabolic effects of antipsychotic drugs. Front Psychiatry. 2012;3:1-12.

Halici Z, Dursun H, Keles ON, Odaci E, Suleyman H, Aydin $\mathrm{N}$, et al. Effect of chronic treatment of haloperidol on the rat liver: a stereological and histopathological study. NaunynSchmiedeberg's Arch Pharmacol. 2009;379(3):253-261.

Halici Z, Keles ON, Unal D, Albayrak M, Suleyman H, Cadirci E, et al. Chronically administered risperidone did not change the number of hepatocytes in rats: a stereological and histopathological study. Basic Clin Pharmacol Toxicol. 2008;102(5):426-432.

Koller EA, Cross JT, Doraiswamy PM, Malozowski SN. Pancreatitis associated with atypical antipsychotics: from the Food and Drug Administration's MedWatch surveillance system and published reports. Pharmacotherapy. 2003a;23(9):1123-1130.
Koller EA, Cross JT, Doraiswamy PM, Schneider BS. Risperidone-associated Diabetes Mellitus: a pharmacovigilance study. Pharmacotherapy. 2003b;23(6):735-744

Mustafa G, Halil O, Elif O, Onur BD, Deniz U, Selina A, et al. Nephrotoxic effects of chronically administered olanzapine and risperidone in male rats. Bull Clin Psychopharmacol. 2012;22(2):139-147.

Pouzet B, Mow T, Kreilgaard M, Velschow S. Chronic treatment with antipsychotics in rats as a model for antipsychoticinduced weight gain in human. Pharmacol Biochem Behav. 2003;75(1):133-140.

Shah R, Subhan F, Ali G, Ullah I, Ullah S, Shahid M, et al. Olanzapine induced biochemical and histopathological changes after its chronic administration in rats. Saudi Pharm J. 2015;24(6):698-704.

Siafaka PI, Barmpalexis P, Lazaridou M, Papageorgiou GZ, Koutris E, Karavas E, et al. Controlled release formulations of risperidone antipsychotic drug in novel aliphatic polyester carriers: Data analysis and modelling. Eur J Pharm Biopharm. 2015;94:473-484.

Terry Jr AV, Hill WD, Parikh V, Waller JL, Evans DR, Mahadik SP. Differential effects of haloperidol, risperidone, and clozapine exposure on cholinergic markers and spatial learning performance in rats. Neuropsychopharmacology. 2003;28(2):300-309.

Weston-Green K, Huang X-F, Deng C. Second generation antipsychotic-induced Type 2 Diabetes: a role for the muscarinic M3 receptor. CNS Drugs. 2013;27(12):1069-1080.

Wirshing DA, Spellberg BJ, Erhart SM, Marder SR, Wirshing WC. Novel antipsychotics and new onset diabetes. Biol Psychiatry. 1998;44(8):778-783.

Yamaguchi I, Hamada K, Yoshida M, Isayama H, Kanazashi S, Takeuchi K. Risperidone attenuates local and systemic inflammatory responses to ameliorate diet-induced severe necrotic pancreatitis in mice: it may provide a new therapy for acute pancreatitis. J Pharmacol Exp Ther. 2009;328(1):256-262.

Received for publication on $16^{\text {th }}$ December 2017 Accepted for publication on $11^{\text {th }}$ February 2018 